\title{
Associating low crystallinity with peroxo groups for enhanced visible light active photocatalysts
}

\author{
Tamás Gyulavári ${ }^{\mathrm{a}, \mathrm{b}}$, Gábor Veréb ${ }^{\mathrm{a}, \mathrm{c}, *}$, Zsolt Pap ${ }^{\mathrm{a}, \mathrm{d}, \mathrm{e}, *}$, András Dombi ${ }^{\mathrm{a}}$, Klára Hernádi ${ }^{\mathrm{a}, \mathrm{b}}$

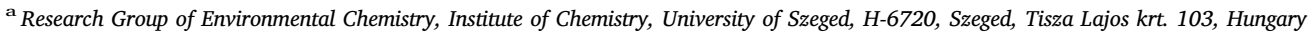 \\ ${ }^{\mathrm{b}}$ Department of Applied and Environmental Chemistry, University of Szeged, H-6720, Szeged, Rerrich tér 1, Hungary \\ ${ }^{\mathrm{c}}$ Department of Process Engineering, Faculty of Engineering, University of Szeged, H-6725, Szeged, Moszkvai krt. 9, Hungary \\ ${ }^{\mathrm{d}}$ Nanostructured Materials and Bio-Nano-Interfaces Center, Interdisciplinary Research Institute on Bio-Nano-Sciences, Babes-Bolyai University, RO-400271, Cluj-Napoca, \\ Treboniu Laurian 42, Romania \\ e Institute of Environmental Science and Technology, University of Szeged, H-6720, Szeged, Tisza Lajos krt. 103, Hungary
}

\section{A R T I C L E I N F O}

\section{Keywords:}

Titanium dioxide

Peroxo group

Phenol

Visible light

Sodium titanate

\begin{abstract}
A B S T R A C T
In the present study hydrogen peroxide was applied during the synthesis of titanium dioxide $\left(\mathrm{TiO}_{2}\right)$ photocatalysts to anchor peroxo groups onto the surface to enhance visible light excitability. The effect of changes in the $\mathrm{pH}$ value and crystallization temperature was investigated. As-prepared peroxo-titania were characterized by X-ray diffraction (XRD), diffuse reflectance spectroscopy (DRS), infrared spectroscopy (IR), Raman spectroscopy and X-ray photoelectron spectroscopy (XPS). The photocatalytic activity was investigated using phenol as model contaminant under visible light irradiation. IR and XPS measurements confirmed the presence of peroxo groups in the samples, moreover Raman and XPS measurements showed the formation of amorphous sodium titanate. Photocatalytic activity measurements pointed out, that most efficient as-prepared photocatalyst exceeded the photocatalytic performance of all reference materials. The cause of the enhanced photocatalytic activity was attributed to the enhanced visible light excitability and considerable amount of peroxo groups, which were not stable after the reusability experiments of the photocatalysts, suffering a redox reaction with the relatively high amount of $\mathrm{Ti}^{3+}$, resulting $\mathrm{Ti}^{4+}$ and surface $\mathrm{OH}$ groups. Therefore, the loss of peroxo groups and concomitantly photocatalytic activity was observed.
\end{abstract}

\section{Introduction}

Titanium dioxide remains to be the benchmark photocatalyst in the field of heterogeneous photocatalysis because of its advantageous properties like non-toxicity, biocompatibility, photostability and low cost [1], such a benchmark does not exist in homogeneous photocatalysis [2,3]. Conventional physicochemical and biological water treatment processes tend to be ineffective against various new type of resistant pollutants which makes the application of $\mathrm{TiO}_{2}$ a suitable alternative. There are numerous publications in which $\mathrm{TiO}_{2}$ was applied to degrade organic contaminants like pesticides (e.g. thiacloprid, dichlorophenoxy acids) $[4,5]$, herbicides (e.g. phenylurea) [6], phenol [7-11], pharmaceuticals (e.g. paracetamol, diclofenac, ethenzamide) $[12,13]$, organic dyes [14-16], furthermore the reactive free radicals formed during the photocatalytic process can also be used efficiently in the removal of various bacteria [17-19]. Besides water purification the utilization of $\mathrm{TiO}_{2}$ in other areas is also extensively investigated for instance air cleaning [20], production of self-cleaning [21] and antibacterial surfaces [22,23], application as dye-sensitized solar cells [24], lithium ion batteries [25], moreover it has great potential to be used for photocatalytic assisted organic synthesis [26], or for the production of hydrogen, an alternate green energy source $[27,28]$. Apart from titanium dioxide's evident advantages the main drawback is its relatively large band gap, which means that undoped titania can only be excited efficiently by UV photons, which limits its practical application possibilities. To overcome this apparent issue great number of approaches have been taken, like doping/modifying with various elements $[14,15,28-30]$ sensitizing with dyes [16,24,31], deposition of noble metals $[7,12]$, or by preparing composites with $\mathrm{WO}_{3}$ [32] or materials like pyrolytic- or activated char [8]. Despite these attempts, synthesizing a versatile, highly efficient visible light active $\mathrm{TiO}_{2}$ at low cost remains to be a challenge.

Among the above-mentioned methods sensitizing titania is an effective way to improve the photocatalytic efficiency by enhancing its light absorption properties. Colon et al. obtained $\mathrm{TiO}_{2}$ photocatalysts by anchoring sulfate groups on its surface resulting in improved photon

\footnotetext{
* Corresponding authors at: Research Group of Environmental Chemistry, Institute of Chemistry, University of Szeged, H-6720, Szeged, Tisza Lajos krt. 103, Hungary

E-mail addresses: verebg@mk.u-szeged.hu (G. Veréb), pzsolt@chem.u-szeged.hu (Z. Pap).
} 
efficiencies $[9,10]$. It was found, that pre-treatment of the $\mathrm{TiO}_{2}$ precursor with sulfate tends to stabilize anatase phase - which is generally considered more active than rutile for photocatalytic applications [33] - moreover, the enhanced photocatalytic activity was attributed to the existence of low hydroxylated surface with oxygen vacancies together with the optimization of redox step in the photocatalytic process. Savinkina et al. compared post-synthesis and simultaneous sensitization methods of $\mathrm{TiO}_{2}$ photocatalysts using methylene blue, methyl red and hydrogen peroxide and it was found, that sensitizing titania during the synthesis (compared to post-synthesis sensitization) resulted in significantly greater photocatalytic efficiencies, which was ascribed to the ability of sensitizer to incorporate into the surface of nano-sized titania [16]. It was also observed, that sensitizing titania with dyes or modifying it using hydrogen peroxide resulted in better photocatalytic activities compared to reference commercial $\mathrm{TiO}_{2}$-s in case of visible light irradiation, although the most prominent increase in activity was noticed in case of hydrogen peroxide, which was attributed to the formation of peroxo chelate complexes resulting in decreased particle sizes. The advantages of applying hydrogen peroxide during the synthesis was also observed in our previous study [34], in which a relatively novel approach was applied to enhance the visible light excitability of rutile titania by anchoring peroxo groups onto the surface. Since anatase is considered to be more active for photocatalytic applications [33], in this study our recent synthesis method was modified to obtain anatase titania and further attempts were made to sensitize the catalyst - thus enhancing its visible light excitability - in a facile, costeffective way.

\section{Experimental}

\subsection{Materials}

For the synthesis of the peroxo-titania, titanium(IV) butoxide (Sigma-Aldrich; reagent grade; 97\%), hydrochloric acid (VWR Chemicals; 37\%), sodium hydroxide (Molar; a.r.; 50\%) hydrogen-peroxide (Sigma-Aldrich; 30\%) and ultrapure water (Millipore Milli-Q) were used. The photocatalytic efficiencies were determined using phenol (Spektrum 3D; analytical grade) as model contaminant. As reference photocatalysts self-made ' $\mathrm{Rutile}-\mathrm{H} 2$ ' $\mathrm{TiO}_{2}$ (which is a peroxo group containing rutile $\mathrm{TiO}_{2}$ with high visible light excitability, published in our recent work [34]) and commercial Evonik Aeroxide P25, Sigma-Aldrich anatase and Sigma-Aldrich rutile were used.

\subsection{Synthesis of the photocatalysts}

The preparation of the peroxo-titania was based on our recent synthesis method [34] in which it was found that in order to anchor peroxo groups on the surface the $n_{\mathrm{Ti}}: n_{\mathrm{H} 2 \mathrm{O} 2}$ ratio has to be set to $1: 2$ (resulting the 'Rutile- $\mathrm{H}_{2}{ }^{\prime} \mathrm{TiO}_{2}$ ). The possible cause of this phenomenon and the different forms of peroxo complexes in case of different $\mathrm{pH}$ conditions were discussed in detail in our previous work [34], and in other scientific publication as well [35]. Considering the above-mentioned reaction parameters, the synthesis was carried out as follows. For the preparation of peroxo titanic acid sol $7.83 \mathrm{~mL} \mathrm{HCl}$ and $6.44 \mathrm{~mL}$ $\mathrm{H}_{2} \mathrm{O}_{2}$ was added to $17.38 \mathrm{~mL}$ Milli-Q water under vigorous magnetic stirring. Subsequently, $10.64 \mathrm{~mL} \mathrm{Ti}(\mathrm{O}-\mathrm{nBu})_{4}$ was added dropwise to the solution at a constant rate of $1 \mathrm{~mL} \mathrm{~min}{ }^{-1}$. The dark orange colored bottom inorganic phase of peroxo-titanium complex $(\mathrm{V}=27.5 \mathrm{~mL})$ was isolated by a separating funnel after $60 \mathrm{~min}$ of phase separation. Hereinafter, the synthesis was modified marginally compared to our previous synthesis method. According to Tang et al. increasing the $\mathrm{pH}$ above 2 results in the formation of anatase phase [36], consequently, the $\mathrm{pH}$ was set to 3 with proper amount of $2 \mathrm{M} \mathrm{NaOH}$. By the addition of $\mathrm{NaOH}$ it was observed, that the crystallization process commenced in less than $24 \mathrm{~h}$ (much sooner than at the original $\mathrm{pH}$ value), thus the sol was aged for $24 \mathrm{~h}$ at $40^{\circ} \mathrm{C}$, then for $24 \mathrm{~h}$ at $55^{\circ} \mathrm{C}$ (sample denoted as
pH3_55) or $70{ }^{\circ} \mathrm{C}$ (sample denoted as pH3_70). As-prepared suspensions were dried at $40{ }^{\circ} \mathrm{C}$ then washed 4 times with Milli-Q water by centrifugation, dried again, then ground in an agate mortar prior further experiments.

\subsection{Characterization methods and instrumentation}

A Rigaku diffractometer was used for the X-ray diffraction (XRD) measurements with the following parameters: $\lambda_{\text {CuKa }}=0.15406 \mathrm{~nm}$, $40 \mathrm{kV}$, and $30 \mathrm{~mA}, 20-40^{\circ}\left(2 \theta^{\circ}\right)$ region. The average primary crystal size values were calculated using the Scherrer equation. The weight fraction of the rutile and anatase phases were estimated from the peak areas at $27.5\left(2 \theta^{\circ}\right)$ and $25.3\left(2 \theta^{\circ}\right)$, respectively.

A Jasco-V650 spectrophotometer with an integration sphere (ILV724) was used for measuring the DR (diffuse reflectance) spectra of the samples $(\lambda=220-800 \mathrm{~nm})$. To obtain the band-gap energy the reflectance data were converted to $F(A)$ values according to the KubelkaMunk theory [37]. The band gap was obtained from the plot of [F(A) $E]^{1 / 2}$ versus energy of the exciting light $(E)$. The possible electron transitions were evaluated by plotting the $d R / d \lambda$ vs. $\lambda$, where $R$ is the reflectance and $\lambda$ is the wavelength [38].

The IR spectra were recorded by using a Bruker Equinox 55 spectrometer. Samples were ground with $\mathrm{KBr}$ pressed into thin pellets (thickness $\sim 0.3 \mathrm{~mm}$ ) and the spectra were recorded with a spectral resolution of $2 \mathrm{~cm}^{-1}$, while the Raman spectra were taken by a Thermo Scientific DXR Raman microscope utilizing $532 \mathrm{~nm}$ laser irradiation.

The specific surface areas of the catalysts were determined by $\mathrm{N}_{2}$ adsorption at $77 \mathrm{~K}$, using a BELCAT-A device. The specific surface area was calculated via the BET method.

XPS measurements were performed on a Specs Phoibos 150 MCD system employing a monochromatic Al- $\mathrm{K}_{\alpha}$ source $(1486.6 \mathrm{eV})$ at $14 \mathrm{kV}$ and $20 \mathrm{~mA}$, a hemispherical analyzer and charge neutralization device. Samples were fixed on a double-sided carbon tape, while it was ensured that the sample covered entirely the tape. Experiments were performed by operating the X-ray source with a power of $200 \mathrm{~W}$, while the pressure in the analysis chamber was in the range of $10^{-9}-10^{-10} \mathrm{mbar}$. The binding energy scale was charge referenced to the $\mathrm{C} 1 \mathrm{~s}$ at $284.6 \mathrm{eV}$. High resolution $\mathrm{O} 1 \mathrm{~s}$ and Ti2p spectra were obtained using analyzer pass energy of $20 \mathrm{eV}$ in steps of $0.05 \mathrm{eV}$. Analysis of the data was carried out with CasaXPS software.

The initial rate of photocatalytic degradation $\left(r_{0}\right)$ was calculated from the slopes of the decay curves $(t=0)$ to evaluate the efficiency of the photocatalysts. The surface normalized values were also determined.

\subsection{Determination of photocatalytic activities}

Photocatalytic performance of the $\mathrm{TiO}_{2}$-s was investigated by the photocatalytic decomposition of phenol under visible light irradiation $(\lambda>400 \mathrm{~nm})$. The photocatalytic experiments were carried out in a double-walled glass vessel (thermostated to $25^{\circ} \mathrm{C}$ ), which was surrounded by 4 conventional energy saving lamps (Düwi 25920/R7S$24 W$ ). The spectrum of the lamps was marginally modified by circulating $1 \mathrm{M} \mathrm{NaNO}_{2}$ solution in the thermostating jacket to cut-off $\mathrm{UV}$ photons $(\lambda<400 \mathrm{~nm}$ ). To maintain the dissolved oxygen level, air was continuously supplied into the suspension using a glass tube. The changes in phenol concentration were measured by an Agilent 1100 series HPLC system equipped with a Lichrospher RP 18 column using methanol/water mixture (50:50) as eluent $(\lambda=210 \mathrm{~nm})$.

For some additional measurements the stability of the peroxo-titania was also investigated. The continuous utilization related experiments were carried out as follows: by the end of the first cycle of phenol degradation measurement the experiment was not terminated but it was continued overnight to decompose the remaining phenol and its degradation intermediates. It should be noted that remaining phenol were still measurable and were $\sim 11.5 \%$ and $\sim 15.1 \%$ of the original 
Table 1

Phase composition, average primer particle sizes, band gaps and specific surface areas of the investigated $\mathrm{TiO}_{2}-\mathrm{S}$.

\begin{tabular}{|c|c|c|c|c|c|c|c|c|c|c|}
\hline \multirow{3}{*}{$\begin{array}{l}\text { Titanium- } \\
\text { dioxide }\end{array}$} & \multicolumn{6}{|c|}{ Phase composition } & \multirow[b]{3}{*}{$\begin{array}{l}\text { Specific surface } \\
\text { area }\left(\mathrm{m}^{2} \mathrm{~g}^{-1}\right)\end{array}$} & \multirow[b]{3}{*}{$\begin{array}{l}\text { Band gap } \\
(\mathrm{eV})\end{array}$} & \multirow[b]{3}{*}{$\begin{array}{l}\mathrm{r}_{0, \text { phenol }} \\
\left(10^{-10} \mathrm{M} \mathrm{s}^{-1}\right)\end{array}$} & \multirow[b]{3}{*}{$\begin{array}{l}\mathrm{r}_{0, \text { phenol }}\left(10^{-12} \mathrm{M} \mathrm{m}^{-2} \mathrm{~s}^{-1}\right) \\
\text { surface normalized }\end{array}$} \\
\hline & \multicolumn{2}{|c|}{ Anatase } & \multicolumn{2}{|l|}{ Rutile } & \multicolumn{2}{|c|}{ Brookite } & & & & \\
\hline & wt $\%$ & $\begin{array}{l}\text { Particle size } \\
(\mathrm{nm})\end{array}$ & wt $\%$ & $\begin{array}{l}\text { Particle size } \\
(\mathrm{nm})\end{array}$ & wt $\%$ & $\begin{array}{l}\text { Particle size } \\
(\mathrm{nm})\end{array}$ & & & & \\
\hline pH3_55 & - & - & - & - & - & - & 120 & 2.34 & 51.3 & 42.7 \\
\hline pH3_70 & 76 & 10.9 & 17 & 8.7 & 7 & 27.5 & 176 & 2.29 & 31.1 & 17.7 \\
\hline Rutile-H2 & - & - & $>99$ & 7 & - & - & 237 & 3.11 & 18.3 & 7.7 \\
\hline AR & 4 & $315^{\text {TEM }}$ & 96 & $315^{\text {TEM }}$ & - & - & 3 & 2.91 & 38.4 & 1280.3 \\
\hline AA & 100 & 85 & - & - & - & - & $<10$ & 3.26 & 6.2 & 68.5 \\
\hline P25 & 90 & 25.4 & 10 & 40 & - & - & 49 & 3.11 & 12.3 & 25.0 \\
\hline
\end{tabular}

phenol concentration (in case of pH3_55 and pH3_70, respectively), and oxidation byproducts also remained in the solution. Then, the $\mathrm{TiO}_{2}$ catalyst was collected (from the previous measurement's samples, which were taken for HPLC measurements) and added to the suspension, and the volume was supplemented to $100 \mathrm{~mL}$, thus setting the initial measurement conditions $\left(\mathrm{c}_{\mathrm{TiO} 2}=1 \mathrm{~g} / \mathrm{L}\right)$ again. Prior the second cycle, the remaining phenol concentration was measured, then proper amount of phenol was further added to the solution thus setting the initial concentration to $10^{-4} \mathrm{M}$ again, then the phenol degradation experiment was carried out the same way.

\section{Results and discussion}

\subsection{Characterization of the photocatalysts}

\subsubsection{Crystal structure and crystal phase composition analysis using X-ray diffraction (XRD)}

Crystal phases of the $\mathrm{TiO}_{2}$-S were identified (Fig. S1), and the mean crystallite sizes (when it was lower than $100 \mathrm{~nm}$ ) were calculated using the Scherrer equation (Table 1). It was found that, Aldrich anatase (AA) contained only anatase (D $=85 \mathrm{~nm}$ ), Aldrich rutile (AR) contained mainly ( $96 \mathrm{wt} \%$ ) rutile (D $\sim 315 \mathrm{~nm}$, determined from TEM micrographs [39]) and a small amount of anatase (4 wt\%), while Evonik Aeroxide P25 (P25) contained $90 \mathrm{wt} \%$ anatase $(\mathrm{D}=25.4 \mathrm{~nm})$ and $10 \mathrm{wt} \%$ rutile $(\mathrm{D}=40 \mathrm{~nm})$. Rutile- $\mathrm{H} 2$ contained only rutile (D $=7 \mathrm{~nm}$ ), pH3_55 $\mathrm{TiO}_{2}$ was almost completely amorphous, while the crystal phase of $\mathrm{pH} 3$-70 $\mathrm{TiO}_{2}$ contained mainly anatase $(76 \mathrm{wt} \%$, $\mathrm{D}=10.9 \mathrm{~nm})$ and non-negligible amounts of rutile $(17 \mathrm{wt} \%)$ and brookite $(7 \mathrm{wt} \%)$ as well. Rutile is generally more active in case of visible light excitation $[40,41]$, still, anatase is considered to be more active for photocatalytic applications [33]. There are some instances in the literature, where mixtures of brookite with anatase and rutile proved to be highly photoactive, because of the presence of junctions among different polymorphic $\mathrm{TiO}_{2}$ phases which enhanced the separation of photogenerated electron-hole pairs [42]. It is well-known that synergistic effect between anatase and rutile phase can occur leading to reduced recombination rate of photogenerated charge carriers [43]. Moreover, amorphous $\mathrm{TiO}_{2}$ generally known nearly inactive due to the facilitated recombination of photogenerated electrons, although in some rare instances amorphous $\mathrm{TiO}_{2}$ was observed to be more active than crystalline $\mathrm{TiO}_{2}$ [44]. As it was presented until now, different crystal phases and amorphous material was also present in the investigated samples. Therefore, the next step was to investigate their optical properties to gain insights concerning their band-structure.

\subsubsection{Optical properties of the investigated materials analyzed by diffuse} reflectance spectroscopy (DRS)

Light absorption properties of the investigated $\mathrm{TiO}_{2}$-s were characterized by DRS measurements (Fig. 1a) and band-gap values (Table 1) were calculated by using the Kubelka-Munk method [37]. In case of AR and Rutile-H2 slight absorption in the visible light region was detected, whereas as expected, reference AA and P25 titania possessed insignificant visible light absorption properties. Most importantly, results pointed out that self-made pH3_55 and pH3_70 titania had greatly enhanced visible light absorption, (a redshift of 131 and $143 \mathrm{~nm}$ was observed, respectively, compared to the Rutile-H2 photocatalyst, which was synthesized without the modification of $\mathrm{pH}$ ) which is in good accordance with the yellow color of the catalysts. Based on the work of Flak et al. [38] by plotting the first-order derivatives of DR spectra as a function of wavelength (Fig. 1b) the visible light excitability properties can be determined more reliably. By applying such an approach, it was found, that the excitability of the latter two self-made titania extended even past the $\sim 550 \mathrm{~nm}$ region, which may be a sign of a color center present (e.g. $\mathrm{Ti}^{3+}$ ) in very low concentrations. Furthermore, in sample pH3_55 two electron-transition bands were observed in the derivative spectrum, one being in the visible- (as already detailed above), while the other one is in the UV region, at $325 \mathrm{~nm}$. The cause of this peculiar peak and the wide visible light absorption was further investigated.

As mentioned in the introduction section, it is necessary to extend titanium dioxide's excitability to the visible light region. There are numerous instances in the literature that by applying different approaches (e.g. doping, deposition of noble metals) successful enhancement of visible light excitability was observed which corresponded well with the resulting photocatalytic efficiency $[12,14,34,45]$. Presumably, the greatly enhanced visible light excitability of pH3_55 and pH3_70 peroxo-titania will be beneficial for the photocatalytic efficiency. However, as all the samples are titania and no doping sources were added, the key to the structure of the materials must be found on the surface of these materials. Furthermore, as the paper deals with amorphous materials as well, according investigation methods should be considered, therefore IR and Raman measurements were carried out.

\subsubsection{Infrared and raman spectroscopy measurements}

Surface properties were evaluated by IR spectroscopy measurements (Fig. 1c) in case of pH3_55, pH3_70 peroxo-titania. Compared to Rutile$\mathrm{H} 2 \mathrm{TiO}_{2}$ (characterized in our recent publication [34]), similarly, the broad band centered at $3400 \mathrm{~cm}^{-1}$ and the sharp band at $1630 \mathrm{~cm}^{-1}$ can be detected, which represent the stretching and bending vibrations of surface $\mathrm{OH}$ groups $[46,47]$, and the small peak at $2357 \mathrm{~cm}^{-1}$ representing bonds containing carbon $[46,48,49]$ can be attributed either to adsorbed $\mathrm{CO}_{2}$ or residual contamination from the $\mathrm{TiO}_{2}$ precursor. At $900 \mathrm{~cm}^{-1}$ a new peak was observed, which can be attributed either to free or complexed -O-O- vibrations $[49,50]$ or the vibration of $\mathrm{Ti}-\mathrm{O}$ bonds within the triangular peroxy titanyl group [48,51,52]. Most importantly, in case of pH3_55 sample, $\mathrm{Ti}-\mathrm{O}-\mathrm{O}$ stretching vibrations (representing peroxo groups at $667 \mathrm{~cm}^{-1}[44,49,53,54]$ ) could be detected, in contrast with Rutile-H2 (and pH3_70) titania, where it was deduced, that the quantity of the peroxo groups was under the threshold of detection of the IR spectrometer and it was only observable by the more sensitive XPS measurements [34]. These apparent differences could be crucial regarding the photocatalytic efficiencies of the investigated $\mathrm{TiO}_{2}$-s. 

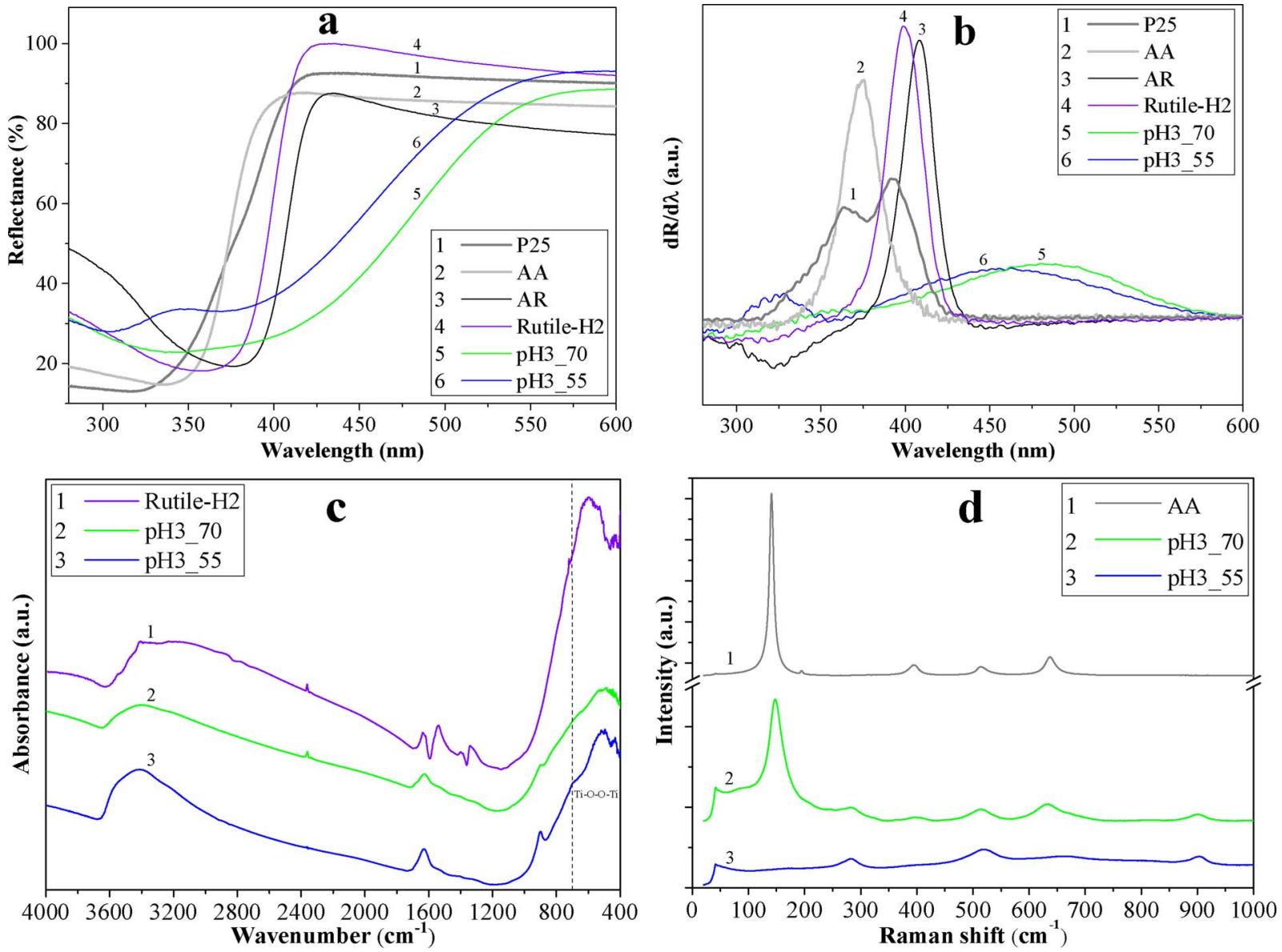

Fig. 1. DR spectra (a), first order derivative of DR spectra (b), IR spectra (c), and Raman spectra (d) of the investigated titania.

When considering the Raman spectra of the samples the following main issues were considered:

- sample pH3_70 contained mostly anatase and low amounts of rutile and brookite as well

- sample pH3_55 was amorphous, no specific signs of any crystal phases were present

- both above-mentioned samples showed unique optical properties

The reference sample in this case was AA, which is a pure anatase phase $\mathrm{TiO}_{2}$. As it can be seen in Fig. 1d sample AA showed the characteristic bands of anatase at $\left(140,394,514\right.$ and $\left.636 \mathrm{~cm}^{-1}\right)$ [55]. These bands were also present in sample pH3_70, which is supported by the information obtained from XRD. However, the amorphous pH3_55 sample showed weak bands of amorphous titania, most probably underway to be crystallized as anatase (bands at 514 and $636 \mathrm{~cm}^{-1}$ ). Even considering this, there were bands, which did not have any correspondence with any titania phase, such as the one located at $367 \mathrm{~cm}^{-1}$, a weak band at $420 \mathrm{~cm}^{-1}$ and an intense one at $900 \mathrm{~cm}^{-1}$. These unidentified bands seem to be related with the unknown band detected in the DR spectrum. As described in Section 2.2 both the samples pH3_55 and pH3_70 were obtained using $\mathrm{NaOH}$. This synthesis method showed similarities with the synthesis of peroxotitanates used for ionic exchange application $[56,57]$. Furthermore, in these two works, the unidentified bands were attributed to different sodium titanates $\left(\mathrm{Na}_{\mathrm{x}} \mathrm{H}_{2-\mathrm{x}} \mathrm{Ti}_{3} \mathrm{O}_{7}\right)$. This new phase may be responsible for the unidentified DRS peak as well, located at $325 \mathrm{~nm}$. This means that the sign of sodium must be detectable.
3.1.4. The surface quality of the chosen catalysts - X-ray photoelectron spectroscopy

In the first instance, the elemental composition was examined and it was found that along the expected elements ( $\mathrm{Ti}$ and $\mathrm{O}$ ), sodium (Na1s binding energy at $1072 \mathrm{eV}$ ) was detected as well, bringing further evidence to the presence of sodium titanates. Furthermore, it should be noted that the values given below are valid for the surface of the materials and they are not total mass reported concentrations.

In the Ti2p spectra of the samples $\mathrm{pH} 355$ and $\mathrm{pH} 3$-70 besides $\mathrm{Ti}^{4+}$, $\mathrm{Ti}^{3+}$ was detected in both samples, which may be responsible for the enhanced visible light absorption properties [58]. In terms of photoactivity the results are controversial in the literature, therefore this issue will not be considered. The amount of $\mathrm{Ti}^{3+}$ in pH3_55 was $35.6 \%$ from the total amount of $\mathrm{Ti}(0.65 \%$ from the total mass), while in case of pH3_70 this value was $25.5 \%$ ( $0.41 \%$ from the total mass). This relatively high amount suggests the presence of low binding energy oxygen (peak location at $529.15 \mathrm{eV}$ ), which was successfully detected in both samples $(20.0 \%$ for pH3_55 and $17.0 \%$ for pH3_70) (Fig. 2). Moreover, expected components were detected in case of titania, such as surface anchored $\mathrm{OH}$ group oxygen $(531.10 \mathrm{eV})$ [59], lattice oxygen $(530.5 \mathrm{eV})$ [59], adsorbed water oxygen $(532.71 \mathrm{eV})$ [60] and more importantly, peroxide related oxygen was also found (which was attributed to peroxo groups originating from $\mathrm{H}_{2} \mathrm{O}_{2}$ used during the synthesis) in both samples at $531.80 \mathrm{eV}$ [61]. This was somewhat expected based on our previous work, the used synthesis procedure and the band detected in the IR spectrum (Section 3.1.3). However, the peroxide type oxygen was detected by IR only in sample pH3_55. This result is in accordance with the XPS measurements, as in sample pH3_55 14.7\%, while in sample pH3_70 only $8.0 \%$ was the ratio of this oxygen type. The fact that the abundance of peroxo group related 

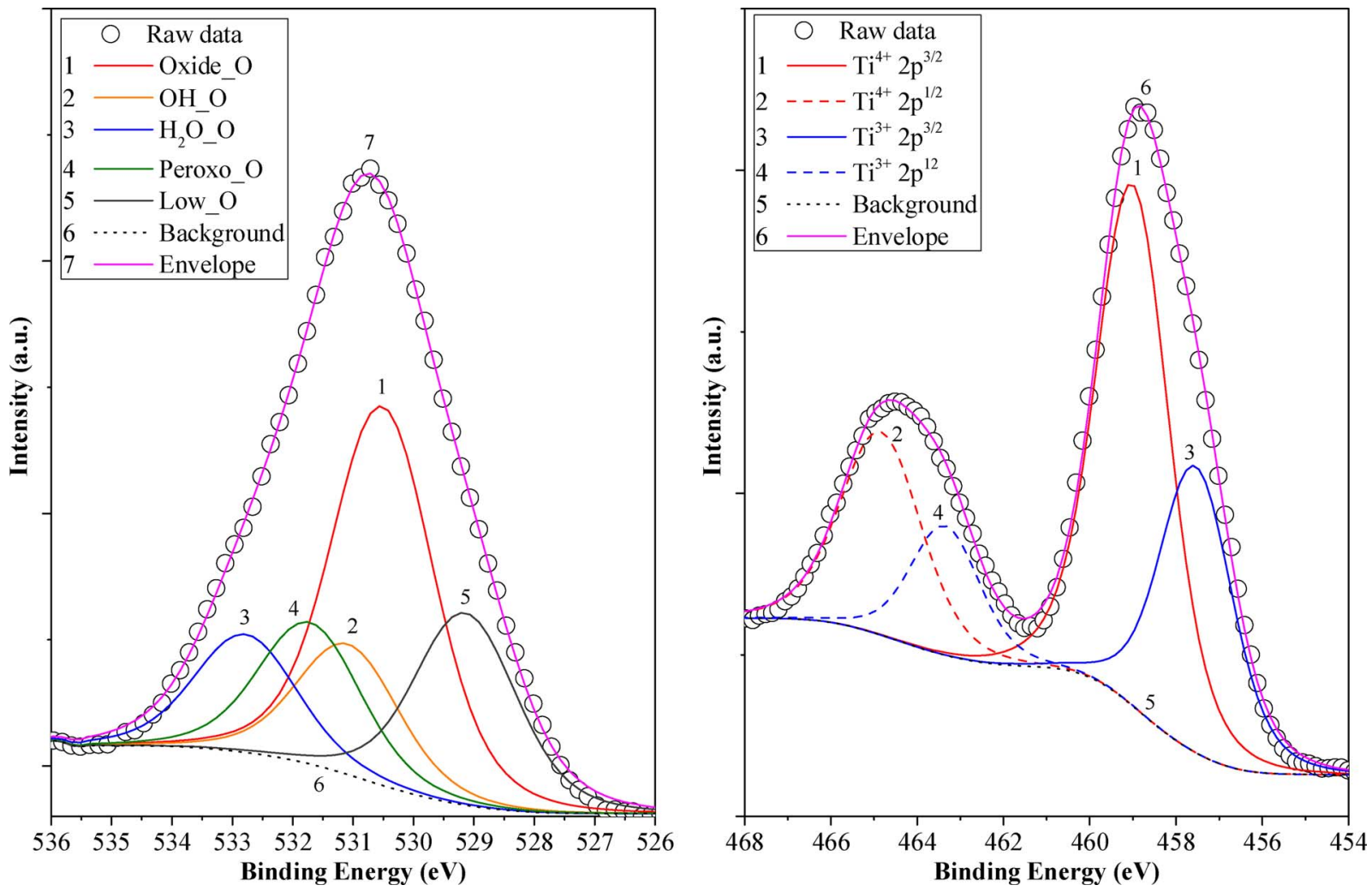

Fig. 2. High-resolution 01 s and Ti2p XPS spectra of pH3_55 sample.

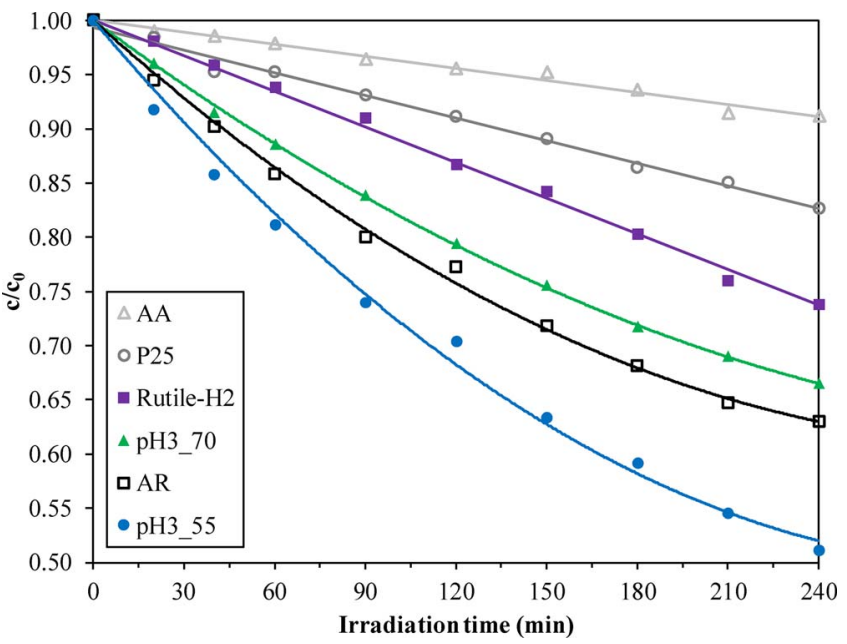

Fig. 3. Decay curves of phenol under VIS irradiation. The initial phenol concentration was set to $0.1 \mathrm{mM}$, and $\mathrm{TiO}_{2}$ concentration was $1.0 \mathrm{~g} \mathrm{~L}^{-1}$ Conventional $24 \mathrm{~W}$ energy saving compact fluorescence lamps with cut-off filtration were used $(\lambda>400 \mathrm{~nm})$.

oxygen is higher in amorphous samples was also observed by Zou et al. [44].

As discussed previously, the samples may contain titanates. By considering this, the peak located at $529.15 \mathrm{eV}$ may be attributed to titanate oxygen as well [62] (a clear deconvolution cannot be carried out as the two species are very close in terms of binding energy), a further evidence in favor of titanates.

\subsubsection{Additional evidence for the presence of titanate}

In sample pH3_55 no crystalline phase was detected, making difficult the identification of any kind of compounds. Therefore, until now the following experimental arguments were brought up to support the presence of sodium titanate:
- The presence of $\mathrm{Na}$ - detected as Na1s in XPS

- Titanate O - detected in O1s XPS

- Electron transition band at $325 \mathrm{~nm}$ in DR spectrum

- Raman bands associated with different titanates

If indeed there is titanate in the mentioned sample, it should be soluble in low concentration aqueous solution of weak organic acids, such as oxalic acid [63], therefore, the following experiment was carried out. Oxalic acid of $0.1 \mathrm{mM}, 0.5 \mathrm{mM}$ and $1 \mathrm{mM}$ containing the pH3_55 $\mathrm{TiO}_{2}$ in $1 \mathrm{~g} \mathrm{~L}^{-1}$ concentration were prepared in which the sample partially dissolved, resulting in the color of the solution to change to yellow (the color of the photocatalyst). The degree and speed of partial dissolution increased as the acidity of the solution increased (by applying more concentrated oxalic acid).

\subsection{Evaluation of photocatalytic activity}

The photocatalyst suspension was left to be stirred in dark for $30 \mathrm{~min}$ to reach adsorption/desorption equilibrium. As expected, the changes in the concentration of phenol were negligible, (and within the range of error of HPLC system), since phenol adsorbs poorly on titania surface [64]. The possibility of photolysis during the degradation of phenol was also excluded in our previous work [39].

The phenol decay curves are presented in Fig. 3. Reference photocatalysts AA and P25 (consisting of entirely or predominantly anatase phase) had low, but notable photocatalytic efficiency, which can be explained by the formation of phenolic complexes on the surface of undoped titanium dioxides which can ultimately lead to the slight absorption of visible light via direct electron transfer between the surface complex and $\mathrm{TiO}_{2}$ conduction band [65-68], resulting a measurable photocatalytic efficiency in case of pure anatase, as it was already observed in our previous publications [19,39]. Additionally, in case of P25, its rutile content also contributed to the measured phenol degradation. All other investigated $\mathrm{TiO}_{2}$-s had higher efficiencies as it was expected, and self-made peroxo-titania where the $\mathrm{pH}$ was modified 
during the synthesis had higher photocatalytic activity compared to the reference Rutile-H2, which was obtained without $\mathrm{pH}$ modification. Most importantly, it was found, that $\mathrm{pH} 3 \_55 \mathrm{TiO}_{2}$ surpassed the photocatalytic efficiency of every investigated titania (49\% of the phenol was degraded), self-made and reference photocatalysts alike, including the most efficient visible light active commercial Aldrich rutile observed by us so far prior this work.

As expected, initial phenol degradation rates $\left(r_{0}\right.$ values in Table 1$)$ followed the same order (AA $<$ P25 $<$ Rutile-H2 $<$ pH3_70 $<$ AR $<$ pH3_55) as decay curves, however, surface normalized photocatalytic efficiencies (Table 1) differed significantly. Aldrich rutile had by far the highest value, which suggests, that peroxo group-containing titania with higher particle size leads to outstanding surface normalized photocatalytic activity. In association with this statement it should be noted that in our previous work [69] it was also proved that the catalysts with higher particle size possessed higher surface normalized photocatalytic efficiency. Additionally, it should be highlighted, that the absolute photocatalytic activity of pH3_55 was 1.65 times higher than pH3_70 photocatalyst's activity despite its 1.47 times lower specific surface area. Therefore, the surface normalized photocatalytic efficiency of pH3_55 was more significantly (2.41 times) higher than the pH3_70 catalyst's (in comparison with the absolute activities). However, it should be mentioned that the absolute activity is more important from the practical point of view.

Additionally, with the applied HPLC method, two main oxidation byproducts of phenol (pyrocatechol and hydroquinone) were detected, and no significant trends were observed in their concentration evolution during the degradation process. The literature based [70-72] possible overall degradation mechanism of phenol (Fig. S2) and a typical (self-measured) HPLC chromatogram (Fig. S3) were included in the supplementary material.

\subsection{Correlating structure, morphology and optical properties}

The high visible light activity of sample pH3 $55 \mathrm{TiO}_{2}$ raised important questions concerning the source of the catalytic property. The first step of the activation is the absorption of visible light photons. This criterion was satisfied for Rutile-H2, pH3_55 and for pH3_70 samples, which were active in visible light. The source of visible light absorption (recorded by DRS) was the presence of $\mathrm{Ti}^{3+}$ centers (proved directly by XPS), and peroxo groups (demonstrated by IR and XPS). The latter one was discussed in-detail in our previous publications [34,69].

The main difficulty in identifying the key property is that sample pH3_55 is amorphous according to XRD, while pH3_70 is a mixture of crystalline anatase, rutile and brookite, while Rutile- $\mathrm{H} 2$ is pure rutile. In case of the latter one, the source of the visible light activity was the presence of the rutile phase (the band-gap of rutile is $3.02 \mathrm{eV}$ ) and the successful anchoring of peroxo groups. In case of sample pH3_70, rutile is not the dominant phase, it contains anatase and peroxo groups as well. In case of this sample the quantity of peroxo groups is higher than in Rutile-H2, while brookite could also contribute to the visible light activity [42].

In case of pH3_55, the amount of the peroxo groups is very high (it was also detectable by IR), the DRS showed similar visible light absorption properties, while it is amorphous and an additional electron transition band was observed in the first derivative of the DR spectrum. Examining more thoroughly the literature, reports concerning amorphous semiconductors and their applicability can be found already dating back to the 1960 's. It was shown, that the semiconductive properties and band-structure of the materials are rather dependent on the interatomic bond length, instead of periodicity and ordered structures [73]. By considering this issue, it was demonstrated successfully that the band-gap of amorphous materials should be higher compared to the crystalline materials, but concomitantly, this favors the appearance of localized states below the conduction band and above the valence band (similarly as in case of doping). These localized pseudo inter-band-gap states may be directly resulted from the presence of titanates/peroxo-titanates deduced by different means in the previous section (greater variability of $\mathrm{Ti}-\mathrm{O}$ bond length - manifested in different oxygen species detected by XPS) and $\mathrm{Ti}^{3+}$. This would explain the double $\mathrm{dR} / \mathrm{d} \lambda$ electron transition bands, one attributed to the bandgap of the material $(\sim 3.4 \mathrm{eV})$ and the other one the inter localized state transitions (visible light absorption band).

Therefore, the functioning of the highly active pH3_55 sample may be explained by the following steps:

a Absorption of the visible light photons

b Charge carrier generation

c Fast separation of the charges in the localized states

d Degradation of model contaminant

The mechanism proposed above may be valid not just in this case, but in other cases as well, where poorly crystalline materials exhibit photocatalytic properties.

\subsection{Reutilization measurements and catalyst stability issues}

The stability of the two (new) self-developed peroxo-titania (pH3_55 and pH3_70) were also investigated (experiment details are shown in Section 2.4). Then, the $\mathrm{TiO}_{2}$ samples were recollected, and XPS measurements were performed.

In our previous study Rutile- $\mathrm{H} 2 \mathrm{TiO}_{2}$ retained its photocatalytic activity (only 5.7\% reduction was observed after 3 reuses), however, during the second cycle of reutilization measurement the observed degradation rate was only $<5 \%$ of the original activity in case of pH3_55 $\mathrm{TiO}_{2}$ and $27.5 \%$ in case of pH3_70 titania.

The activity decrease of the used photocatalysts should be examined and explained carefully considering two main aspects:

- The first one is the origin of the activity decrease, which is mandatory;

- The second one is to search and find a suitable correlation between the obtained activity decrease and morpho-structural properties and eventually a trend within the samples.

The structural entities which can be responsible for the activity itself, are multiple, therefore the most obvious one was chosen, namely the presence of peroxo groups. XPS measurements were carried out for the sample which was collected after the reutilization experiments, and before the measurements the powder was washed and dried (to remove any adsorbed organic material, which may influence the O1s XPS spectrum). It was found that the peroxo group ratio diminished in the case of sample pH3_55 from $14.7 \%$ to $1.3 \%$ (from the total amount of surface oxygen atoms), which correlates well with the findings of Shankar et al. where the decomposition of peroxo species after the experiments was confirmed by FTIR and UV-vis spectroscopy [53]. Simultaneously, a decrease of $\mathrm{Ti}^{3+}$ was also observed from $35.6 \%$ to $26.5 \%$ (from the total amount of surface titanium atoms) and in value a similar increase was found for the $\mathrm{OH}_{-} \mathrm{O}$ O1s signal (surface $\mathrm{OH}$ group related oxygen, $12.1 \%$ increase), for the Oxide_O O1s signal (lattice oxygen, $1.3 \%$ increase) and for $\mathrm{Ti}^{4+}$ (9.1\% increase). This suggested that by illuminating the surface of the catalyst the following reactions probably occurred:

- $\mathrm{The}^{\mathrm{Ti}^{3+}}$ centers which were located near to a surface peroxo group, transformed from $\mathrm{Ti}^{3+}$ to $\mathrm{Ti}^{4+}: \mathrm{Ti}^{3+} \rightarrow \mathrm{Ti}^{4+}+\mathrm{e}^{-}$

- The above-mentioned electron can be captured by a photogenerated hole, or can act as a reductive agent as follows: Ti-O-O$\mathrm{Ti}_{\text {(peroxo) }}+2 \mathrm{e}^{-}+2 \mathrm{H}^{+} \rightarrow 2 \mathrm{Ti}-\mathrm{OH}^{*}$

(* the proton originates from the slightly acidic phenol solution, while the resulting entities are surface anchored hydroxyl groups). 
This redox couple may be the main cause of the activity deterioration. If this should be the case then it must be valid for the other samples as well, a fact which may take the explanation to the second aspect mentioned above.

The main correlation found concerning the different samples were the following: as the crystallinity increased (evaluated by comparing the diffraction peak areas of self-made samples to commercial titania diffraction peak areas consisting of $100 \%$ crystalline phase; $<1 \%, 25 \%$ and $72 \%$ crystalline phase was calculated for pH3_55, pH3_70 and Rutile-H2, respectively), the stability of the peroxo group increased as well and the activity decrease was less or none at all (>95\%, 72.5\% and 5.7\% activity decrease for pH3_55, pH3_70 and Rutile-H2, respectively). This is a rather surprising, but somehow evident explanation, because it is known that highly active titania systems contain sometimes oxygen vacancies $/ \mathrm{Ti}^{3+}$ centers in highly crystalline structures $[59,74]$. Nevertheless, it can be found in the literature the so called black titania, which contains a relatively high amount of $\mathrm{Ti}^{3+}$ which is also crystalline and stable, suggesting that this specie is stable when it is in a crystalline structure or embedded in such one [75]. If amorphous vs. crystalline structures are compared it is evident, that in the amorphous one the above-mentioned redox reaction couple is facilitated, while in crystalline structures it is inhibited due to the neighboring stabilization effects (fact demonstrated by the detection of $\mathrm{Ti}^{3+}$ after calcination in air) [59,74].

Therefore, it is clear now, that a certain degree of crystallinity is needed to preserve the activity enhancement conferred by the peroxo groups, but other aspects may also contribute to the stability, which were not investigated, namely the relative concentration of the peroxo group itself.

\section{Conclusions}

In this study, visible light active titanium dioxides containing peroxo groups were synthesized in a facile, cost-effective way without the need of calcination. Application of $55^{\circ} \mathrm{C}$ and $70{ }^{\circ} \mathrm{C}$ as crystallization temperature resulted in either amorphous, or predominantly anatase phase peroxo-titania. DRS measurements pointed out that increasing the $\mathrm{pH}$ to 3 during the synthesis resulted in immensely increased visible light excitability of self-made peroxo-titania, due to the appearance of localized states within the band-gap, which originated presumably from the amorphous nature of the material and its chemical composition (sodium titanites, amorphous titania, $\mathrm{Ti}^{3+}$ ). In case of $\mathrm{pH}_{3} 55 \mathrm{TiO}_{2}$ the presence of sodium titanate was demonstrated directly by DRS- (electron-transition band located in the UV region), Raman- (bands at 514 and $636 \mathrm{~cm}^{-1}$ ) and XPS (Na1 s binding energy at $1072 \mathrm{eV}$ ) measurements, and indirectly by its dissolution in oxalic acid. Moreover, XPS (and IR measurements in case of pH3_55 sample) confirmed the presence of peroxo groups, which together with the above-mentioned structural entities were deduced to be responsible for the greatly enhanced photocatalytic activity of sample pH3_55 which exceeded the photocatalytic efficiency of all investigated titania. Further XPS measurements revealed, that a certain degree of crystallinity is required to preserve the activity enhancement caused by the peroxo groups.

\section{Acknowledgements}

This study was financed by the GINOP-2.3.2-15-2016-00013 project. This project was supported by the János Bolyai Research Scholarship of the Hungarian Academy of Sciences. The research was partially co-financed by the Swiss Contribution $(\mathrm{SH} / 7 / 2 / 20)$. The authors are grateful for Zsejke Tóth, Kornélia Baán and Milica Todea for the contribution in Raman, BET and XPS measurements, respectively.

\section{Appendix A. Supplementary data}

Supplementary data associated with this article can be found, in the online version, at https://doi.org/10.1016/j.cattod.2017.11.027.

\section{References}

[1] M. Iwase, K. Yamada, T. Kurisaki, O.O. Prieto-Mahaney, B. Ohtani, H. Wakita, Appl Catal. B Environ. 132-133 (2013) 39-44.

[2] M.H. Shaw, J. Twilton, D.W. MacMillan, J. Org. Chem. 81 (2016) 6898-6926.

[3] J. Xie, H. Jin, A.S.K. Hashmi, Chem. Soc. Rev. 46 (2017) 5193-5203.

[4] M. Abdennouri, M. Baâlala, A. Galadi, M. El Makhfouk, M. Bensitel, K. Nohair, M. Sadiq, A. Boussaoud, N. Barka, Arab. J. Chem. 9 (2016) S313-S318.

[5] G. Rózsa, Z. Kozmér, T. Alapi, K. Schrantz, E. Takács, L. Wojnárovits, Catal. Today 284 (2017) 187-194.

[6] K. Kovacs, J. Farkas, G. Vereb, E. Arany, G. Simon, K. Schrantz, A. Dombi, K. Hernadi, T. Alapi, J. Environ. Sci. Heal. B 51 (2016) 205-214.

[7] S. Fodor, G. Kovács, K. Hernádi, V. Danciu, L. Baia, Z. Pap, Catal. Today 284 (2017) $137-145$.

[8] M. Antonopoulou, P. Karagianni, A. Giannakas, V. Makrigianni, E. Mouzourakis, Y. Deligiannakis, I. Konstantinou, Catal. Today 280 (2017) 114-121.

[9] G. Colón, M.C. Hidalgo, J.A. Navío, Appl. Catal. B Environ. 45 (2003) 39-50.

[10] G. Colón, M.C. Hidalgo, M. Macías, J.A. Navío, Appl. Catal. A Gen. 259 (2004) $235-243$.

[11] G. Veréb, Z. Ambrus, Z. Pap, K. Mogyorósi, A. Dombi, K. Hernádi, React. Kinet Mech. Catal. 113 (2014) 293-303.

[12] W. Lin, H. Zheng, P. Zhang, T. Xu, Appl. Catal. A Gen. 521 (2016) 75-82.

[13] M. Gar Alalm, A. Tawfik, S. Ookawara, J. Environ. Chem. Eng. 4 (2016) 1929-1937.

[14] Q. Guo, Z. Zhang, X. Ma, K. Jing, M. Shen, N. Yu, J. Tang, D.D. Dionysiou, Sep. Purif. Technol. 175 (2017) 305-313.

[15] P. Nyamukamba, L. Tichagwa, J.C. Ngila, L. Petrik, J. Photoch. Photobio. A 343 (2017) 85-95.

[16] E. Savinkina, L. Obolenskaya, G. Kuzmicheva, Appl. Nanosci. 5 (2014) 125-133.

[17] S. Malato, M.I. Maldonado, P. Fernández-Ibáñez, I. Oller, I. Polo, R. SánchezMoreno, Mat. Sci. Semicon. Proc. 42 (2016) 15-23.

[18] G.F. Samu, Á. Veres, S.P. Tallósy, L. Janovák, I. Dékány, A. Yepez, R. Luque, C. Janáky, Catal. Today 284 (2017) 3-10.

[19] G. Veréb, L. Manczinger, G. Bozsó, A. Sienkiewicz, L. Forró, K. Mogyorósi, K. Hernádi, A. Dombi, Appl. Catal. B Environ. 129 (2013) 566-574.

[20] M. Krichevskaya, S. Preis, A. Moiseev, N. Pronina, J. Deubener, Catal. Today 280 (2017) 93-98.

[21] D.M. Giolando, Sol. Energy 124 (2016) 76-81.

[22] C. Han, J. Lalley, D. Namboodiri, K. Cromer, M.N. Nadagouda, Curr. Opin. Chem. Eng. 11 (2016) 46-51.

[23] V. Scuderi, M.A. Buccheri, G. Impellizzeri, A. Di Mauro, G. Rappazzo, K. Bergum, B.G. Svensson, V. Privitera, Mat. Sci. Semicon. Proc. 42 (2016) 32-35.

[24] M. Gratzel, Inorg. Chem. 44 (2005) 6841-6851.

[25] M. Wagemaker, A.P. Kentgens, F.M. Mulder, Nature 418 (2002) 397-399.

[26] V. Augugliaro, T. Caronna, A. Di Paola, G. Marcì, M. Pagliaro, G. Palmisano, L. Palmisano, Environ. Benign Photocatal. Nanostruct. Sci. Tech. 26 (2010) 623-645.

[27] G.N. Nomikos, P. Panagiotopoulou, D.I. Kondarides, X.E. Verykios, Appl. Catal. B Environ. 146 (2014) 249-257.

[28] A. Samokhvalov, Renew. Sust. Energ. Rev. 72 (2017) 981-1000.

[29] B. László, K. Baán, E. Varga, A. Oszkó, A. Erdőhelyi, Z. Kónya, J. Kiss, Appl. Catal. B Environ. 199 (2016) 473-484.

[30] Z. Pap, K. Mogyorósi, G. Veréb, A. Dombi, K. Hernádi, V. Danciu, L. Baia, J. Mol. Struct. 1073 (2014) 157-163.

[31] Y. Cho, W. Choi, C.-H. Lee, T. Hyeon, H.-I. Lee, Environ. Sci. Technol. 35 (2001) 966-970.

[32] É. Karácsonyi, L. Baia, A. Dombi, V. Danciu, K. Mogyorósi, L.C. Pop, G. Kovács, V. Coşoveanu, A. Vulpoi, S. Simon, Z. Pap, Catal. Today 208 (2013) 19-27.

[33] M.A. Fox, M.T. Dulay, Chem. Rev. 93 (1993) 341-357.

[34] T. Gyulavári, Z. Pap, G. Kovács, L. Baia, M. Todea, K. Hernádi, G. Veréb, Catal. Today 284 (2017) 129-136.

[35] J. Mühlebach, K. Müller, G. Schwarzenbach, Inorg. Chem. 9 (1970) 2381-2390.

[36] Z.L. Tang, J.Y. Zhang, Z. Cheng, Z.T. Zhang, Mat. Chem. Phys. 77 (2003) 314-317.

[37] P. Kubelka, F. Munk, Zeit. Tech. Phys. 12 (1931) 593-601.

[38] D. Flak, A. Braun, B.S. Mun, J.B. Park, M. Parlinska-Wojtan, T. Graule, M. Rekas, Phys. Chem. Chem. Phys. 15 (2013) 1417-1430.

[39] G. Veréb, Z. Ambrus, Z. Pap, Á. Kmetykó, A. Dombi, V. Danciu, A. Cheesman, K. Mogyorósi, Appl. Catal. A Gen. 417-418 (2012) 26-36.

[40] S. Yin, H. Hasegawa, D. Maeda, M. Ishitsuka, T. Sato, J. Photoch. Photobiol. A 163 (2004) 1-8.

[41] J. Noh, M. Yi, S. Hwang, K.M. Im, T. Yu, J. Kim, J. Ind. Eng. Chem. 33 (2016) 369-373.

[42] A. Di Paola, M. Bellardita, L. Palmisano, Catal 3 (2013) 36-73.

[43] K.E. Rajashekhar, L.G. Devi, J. Mol. Catal. A Chem. 374-375 (2013) 12-21.

[44] J. Zou, J. Gao, F. Xie, J. Alloy. Compd. 497 (2010) 420-427.

[45] Á. Kmetykó, Á. Szániel, C. Tsakiroglou, A. Dombi, K. Hernádi, React. Kinet. Mech. Catal 117 (2015) 379-390.

[46] J. Orlikowski, B. Tryba, J. Ziebro, A.W. Morawski, J. Przepiórski, Catal. Commun. 24 (2012) 5-10.

[47] X. Ye, C. Zheng, L. Ma, X. Huang, Mat. Sci. Semicon. Proc. 31 (2015) 295-301.

[48] C.G. Silva, J.L. Faria, Photochem. Photobiol. Sci. 8 (2009) 705-711.

[49] M.R. Ayers, A.J. Hunt, Mater. Lett. 34 (1998) 290-293.

[50] P. Tengvall, L. Bertilsson, B. Liedberg, H. Elwing, I. Lundström, J. Colloid Interf. Sci. 139 (1990) 575-580. 
[51] T. Busani, R.A.B. Devine, Semicon. Sci. Tech. 20 (2005) 870-875.

[52] G.V. Jere, C.C. Patel, Can. J. Chem. 40 (1962) 1576-1578.

[53] M.V. Shankar, T. Kako, D. Wang, J. Ye, J. Colloid Interf. Sci. 331 (2009) 132-137.

[54] V. Etacheri, M.K. Seery, S.J. Hinder, S.C. Pillai, Adv. Funct. Mater. 21 (2011) 3744-3752.

[55] T. Ohsaka, J. Phys. Soc. Jpn. 48 (1980) 1661-1668.

[56] R.A. Zárate, S. Fuentes, J.P. Wiff, V.M. Fuenzalida, A.L. Cabrera, J. Phys. Chem. Solids 68 (2007) 628-637.

[57] W.-D. Yang, C.T. Nam, J.-C. Chung, H.-Y. Huang, J. Nanomater. 2016 (2016) 1-9.

[58] L.-B. Xiong, J.-L. Li, B. Yang, Y. Yu, J. Nanomater. 2012 (2012) 1-13.

[59] Z. Pap, V. Danciu, Z. Cegléd, Á. Kukovecz, A. Oszkó, A. Dombi, K. Mogyorósi, Appl. Catal. B Environ. 101 (2011) 461-470.

[60] C.D. Wagner, D.A. Zatko, R.H. Raymond, Anal. Chem. 52 (1980) 1445-1451.

[61] D. Foix, M. Sathiya, E. McCalla, J.-M. Tarascon, D. Gonbeau, J. Phys. Chem. C 120 (2016) 862-874.

[62] M.E. Pilleux, C.R. Grahmann, V.M. Fuenzalida, J. Am. Ceram. Soc. 77 (1994) 1601-1604.

[63] C.M. Rodrigues, O.P. Ferreira, O.L. Alves, J. Brazil. Chem. Soc. 21 (2010)
1341-1348.

[64] D. Robert, S. Parra, C. Pulgarin, A. Krzton, J.V. Weber, Appl. Surf. Sci. 167 (2000) 51-58.

[65] A.G. Agrios, K.A. Gray, E. Weitz, Langmuir 19 (2003) 1402-1409.

[66] A.G. Agrios, K.A. Gray, E. Weitz, Langmuir 20 (2004) 5911-5917.

[67] S. Kim, W. Choi, J. Phys. Chem. B 109 (2005) 5143-5149.

[68] Y. Cho, H. Kyung, W. Choi, Appl. Catal. B Environ. 52 (2004) 23-32.

[69] G. Veréb, T. Gyulavári, Z. Pap, L. Baia, K. Mogyorósi, A. Dombi, K. Hernádi, RSC Adv 5 (2015) 66636-66643.

[70] E. Grabowska, J. Reszczynska, A. Zaleska, Water Res. 46 (2012) 5453-5471.

[71] G. Vardar, T.K. Wood, Appl. Environ. Microbiol. 70 (2004) 3253-3262.

[72] Z. Wang, W. Cai, X. Hong, X. Zhao, F. Xu, C. Cai, Appl. Catal. B Environ. 57 (2005) 223-231.

[73] C. Feldman, K. Moorjani, APL Tech. Digest (1968) 2-9.

[74] Z. Pap, É. Karácsonyi, Z. Cegléd, A. Dombi, V. Danciu, I.C. Popescu, L. Baia, A. Oszkó, K Mogyorósi, Appl CataliB Environ. 111-112 (2012) 595-604.

[75] Y. Liu, L. Tian, X. Tan, X. Li, X. Chen, Sci. Bull. 62 (2017) 431-441. 